\title{
Population, Morphology and Ultrastructures Gonads Adaptation Changed Between Unsuitable and Original Breeding Habitats in Oncomelania hupensis
}

\section{Feng Miao}

Shandong Institute of Parasitic Diseases

\section{Zhongdao Wu}

Sun Yat-sen University Zhongshan School of Medicine

\section{Xin Zeng}

Sun Yat-sen University Zhongshan School of Medicine

\section{Jinlang Wu}

Sun Yat-sen University Zhongshan School of Medicine

Xin Liu

Shandong Instititue of Parasitic Diseases

Chongxing Zhang ( $\nabla$ chongxingzhang@aliyun.com )

Shandong Institute of Parasitic Diseases https://orcid.org/0000-0001-5529-6783

\section{Research article}

Keywords: Oncomelania hupensis snail, Unsuitable breeding habitat, Gonad, East Route of South-to-North Water Diversion Project, Transmission electron microscopy

Posted Date: August 24th, 2020

DOl: https://doi.org/10.21203/rs.3.rs-44835/v1

License: (c) (1) This work is licensed under a Creative Commons Attribution 4.0 International License. Read Full License 


\section{Abstract}

Background: Weishan Lake and its surrounding areas represent an important water conduit and storage reservoirs for the Eastern Route due to the South to North Water Diversion Project. It was listed as a potential endemic area for schistosomiasis by the Ministry of Health Schistosomiasis Advisory Committee. Oncomelania hupensis is the unique intermediate host of Schistosoma japonicum in China. To determine whether Oncomelania hupensis could establish colonies in Weishan Lake once introduced from original habitat, in May 2004, 2000 adult Oncomelania hupensis were transplanted from the original habitat to isolated snail cages in Weishan Lake.

Results: From October 2005 to October 2016, Oncomelania hupensis were bred in isolated snail cages in Weishan Lake, and samples of the original habitats were collected. The population was monitored, and the morphology of Oncomelania hupensis was measured. Gonads were sectioned and observed under transmission electron microscopy. Oncomelania hupensis could still continually reproduce its population 12 years after transplantation to Weishan Lake. Comparing the morphology with that of animals from the original habitat, it was found that the snail shell length, shell width and aperture width decreased in 2005, and significant changes were observed in the ultrastructure of sperms (axoneme and the $9+2$ the axoneme coarse fibers were absent, and chromatin density decreased in the head of the sperm cells) and oocytes (nucleus swelling, endoplasmic reticulum, pale vesicles and lipidosomes decreased and chromatin was absent) of snails breeding in Weishan Lake.

Conclusions: Although abnormal development of the ultrastructure of Oncomelania hupensis reproductive gonad was observed, they still survived for 12 years, which might reflect a survival strategy in which the snail trades a degree of fecundity to survive though harsh winters.

\section{Background}

Oncomelania hupensis (Gredler, 1881) is the unique intermediate host of Schistosoma japonicum (Katsurada, 1904) in eastern and southeastern Asian countries, particularly in China, where it still is an important public health problem[1]. $O$. hupensis is widely distributed in many schistosomiasis epidemic areas of China, such as lakes/marshlands and water channel areas of the Yangtze River[2]. Southern China is rich in water resources, while northern China lacks them. Thus, a nationwide project, the Southto-North Water Diversion Project (SNWD Project), was carried out to solve this problem. Due to the SNWD Project in the Yangtze River[3], 0 . hupensis currently exists in intake areas of the East Route of the project[4]. The northernmost boundary of the natural distribution area of 0 . hupensis in China is $33^{\circ} 15^{\prime}[3]$. Weishan Lake $\left(35^{\circ} 05^{\prime} \mathrm{N}, 116^{\circ} 44^{\prime} \mathrm{E}\right)$ in Shangdong Province is the largest lake in northern China. The highest temperature and lowest temperature in the most recent eight years were $37^{\circ} \mathrm{Cand}-13^{\circ} \mathrm{C}$ respectively. Weishan Lake is considered to be unsuitable breeding habitat for $O$. hupensis. However, Weishan Lake is an important water conduit (conveyance corridor) and storage reservoir for the Eastern Route of the SNWD Project. Concerns had been raised that $O$. hupensis could become distributed further north by SNWD Project. 
Many widely range distributed mollusks have potential abilities to adapt to cold or unsuitable environments. Invasive blue mussels can modify their protein stability to increase cold tolerance[5]. Octopus can survive in polar regions by increasing the oxygen binding ability of hemocyanin[6]. An equatorial freshwater snail, Clea nigricans, has tolerance for heating and cooling exceeding the average daily maximum and minimum temperatures by approximately $20^{\circ} \mathrm{C}[7]$. Using a supercooling strategy, the rock-dwelling snail Chondrina avenacea could survive temperatures as low as $-20^{\circ} \mathrm{C}[8]$.

We hypothesized that $O$. hupensis might use certain strategies to adapt to unsuitable environments. Therefore, based on this hypothesis, we believed that once introduced to Weishan Lake, $O$. hupensis could establish colonies. Dushan Island, one of four major islands in Weishan Lake, is the most isolated. It has a vast area of marshland intertidal zone and a $150 \mathrm{~m}$ high mountain. A neglected fish pond near the marshland south of the mountain was selected as the experimental field. In October 2004, O. hupensis collected from Yangtze River were transplanted.

In this study, we carried out a 12-year field observation on the 0 . hupensis population and its morphology in a transplanted habitat to determine whether $O$. hupensis could establish colonies in northern China and what changes would occur in the snails once introduced by the South to North Water Diversion Project.

\section{Results}

\section{Field sampling results of Weishan Lake}

From 2004 to 2016 the snail population was continually monitored. Each year, 1/10 of the volume of the soil in breeding cages was sampled, and live snails were counted to estimate the total population. Fluctuating snail populations, ranging from 1590 to 14550, were observed (Fig. 3A). In the first year, the population rapidly increased more than 3 times the initial population (from 2000 to 8230 ) from 2005 to 2006, and then it slowly dropped down to 1580 from 2007 to 2009. Between 2010 and 2013, the population dramatically increased to more than 7 times the initial population to 14550; however, a sharp drop was again observed again from 2014 to 2016, and the population decreased to 1590 in 2016.

Snail eggs were also collected and counted to estimate the productivity of the snails. The number of eggs laid per female snail was 27.73 in 2005, 6.29 in 2006, 1.6 in 2015 and 0.7 in 2016 (Fig. 3B).

\section{Shell morphology of $\boldsymbol{O}$. hupensis collected from Yangtze River and Weishan Lake}

In 2004, 2005, 2006, 2015 and 2016 snails were collected both from Yangtze River and Weishan Lake to compare their morphological features. The shell length $(L)$, shell width $(W)$, aperture length $(A L)$, aperture width (AW) and longitudinal ridge number (LRN) of the collected snails were measured.

The average shell length of snails in the Yangtze River and Weishan Lake ranged from $5.87 \pm 1.27 \mathrm{~mm}$ to $7.33 \pm 0.63 \mathrm{~mm}$ (Fig. 4A). The average shell width of snails in the Yangtze River ranged from $2.50 \pm$ $0.48 \mathrm{~mm}$ to $3.43 \pm 0.27 \mathrm{~mm}$ (Fig. 4B). The average aperture length of snails in the Yangtze River and Weishan Lake ranged from $1.58 \pm 0.21 \mathrm{~mm}$ to $2.52 \pm 0.22 \mathrm{~mm}$ (Fig. 4C). The average aperture width of 
snails in the Yangtze River and Weishan Lake ranged from $1.57 \pm 0.34 \mathrm{~mm}$ to $2.33 \pm 0.33 \mathrm{~mm}$ (Fig. 4D). The average longitudinal ridge number of snails in Yangtze River and Weishan Lake ranged from $12.41 \pm$ 2.61 to $13.75 \pm 1.24$ (Fig. 4E).

No significant difference in any of the 5 features of snail morphology was observed between different times and locations, although decreases in shell length (L), shell width (W) and aperture width (AW) were observed after 2005 in the snails of Weishan Lake when compared to the ones from the Yangtze River.

\section{Gonad ultrastructure of 0 . hupensis from Yangtze River and Weishan Lake}

In sections of male gonads of snails from Yangtze River, sperm cells could be divided into head, neck, middle piece and principal piece of tail (Fig. 5A). In the head region, the acrosome is separated from helical chromatin and composed of electron opaque material, similar to the nucleus. The nucleus is long and helical, while the plasma membrane surrounding the nucleus is rough, with space between it and the nuclear membrane. The neck region is defined as the area connecting the head and middle piece, composed of nuclear fossa (NF) and nuclear invagination (NI). The NF is a lumen connecting to middle piece, and $\mathrm{Nl}$ is formed by chromatin projected on the neck (Fig. 5A). Observation of a cross-section of NF demonstrates electron lucent material in the center which forms the axoneme (Fig. 5B). A cross-section shows that the middle piece (MP) of the tail consists of the axoneme coarse fiber (ACF) complex in the center, surrounded by mitochondrial sheath (MS). The axoneme is composed of nine peripheral microtubular doublets and a central doublet, $9+2$ (Fig. 5C). The mitochondrial sheath is composed of 9 regularly arranged mitochondria bunches; each bunch contains 5 mitochondria (Fig. 5C). The mitochondrial sheath is absent in the principal piece (PP) of the tail. A cross-section shows the $9+2$ structure surrounded by the fibrous sheath (FS), which forms a ninogan-shaped lumen. Outermost is the loosely surrounding plasma membrane (PM). ACF is surrounded by electron lucent material (Fig. 5D).

In sections of male gonads of snails from Weishan Lake, the main features are the same as those in the snails from the Yangtze River. However, some changes in detailed features were observed. In the head region, the nucleus had lower nuclear electron density than in those from the Yangtze River; in the neck region, axoneme is missing from the NF (Fig. 6B), and in the middle piece and principle piece, the $9+2$ ACF structure is absent (Fig. $6 \mathrm{C}$ and D).

For female gonads of snails from the Yangtze River, oocytes are observed in the primary follicles of $O$. hupensis. Abundant endoplasmic reticulum (ER) and lipidosomes $(L)$ with electron-opaque interiors are distributed in the cytoplasm. Pale vesicles (PV) are visible in extracellular areas. The nuclear membrane (NM) is irregular in shape and attached to a large amount of ER. The nucleolus is round in shape with high electron density; abundant chromatin $(\mathrm{Cr})$ and a small amount of heterochromatin $(\mathrm{HCr})$ are distributed inside the nucleus (Fig. 7).

For oocytes of snails from Weishan Lake, ER, PV and L are much reduced in the cytoplasm when comparied to those from the Yangtze River. The nucleus is relatively larger in size, the NM is smooth and 
round in shape, without visible ER attached, and the nucleolus and $\mathrm{Cr}$ are not visible in the nucleus (Fig. 8).

\section{Discussion}

In this study, we performed a 12-year observation on 0 . hupensis transplanted from the Yangtze River to Weishan Lake of Shandong Province. Although the transplantation was carried out under an artificially restricted environment, and the productivity of snails dropped from 27.73 eggs/snail to 0.7 eggs/snail, we found that snails could still continually reproduce their population. In the morphology of snails, we observed a decrease (not significant) in shell length (L), shell width (W) and aperture width (AW) after 2005 when compared to snails from the Yangtze River. To further reveal the changes occurring in the snails during transplantation, we observed the ultrastructure of the reproductive gonad. Our results indicated that the axoneme and $9+2$ ACF were absent in sperm tails and chromatin density was decreased in the sperm heads of snails from Weishan Lake. Meanwhile, swelling nuclei decreased endoplasmic reticulums, pale vesicles and lipidosomes and absent chromatin were observed in oocytes.

According to reports of the Chinese CDC, until 2016, Shandong province Province has not been an endemic area of $S$. japonicum, and no local cases of human infection were reported[9]. O. hupensis is mainly distributed in southern China below $33^{\circ} 15^{\prime}$, and no snails had been found in Shandong Province. However, due to the South to North Water Diversion Project (SNWD Project), Weishan Lake and its surrounding areas, as an important water conduit (conveyance corridor) and storage reservoir for the project, was listed as a potential new endemic area for schistosomiasis by the Ministry of Health Schistosomiasis Advisory Committee in 2008[10]. By artificially transplanting 0 . hupensis to Weishan Lake in 2004, we observed a fluctuating but continuous snail population over 12 years. The initial population of snails was 2000 , and during the 12-year observation, the total population ranged from 1580 to 14550 . The curve of the snail population reflected 2 peaks; the first peak occurred within approximately the first 2 years $(2005,2006)$, with the total number of snails rapidly increasing from the initial 2000 to 8230. Then the population dropped down to the initial numbers. The second peak occurred in 20102013 , reaching a snail population of 14550 ; then, again, the population quickly decreased to 1590 . This fluctuation of population might result from limited living space and nutrition, as all transplantation experiments were carried out in man-made breeding cages with nets to prevent snails escaping to the outside. When the snail population reached the limits of the breeding cage, the death rate of snails increased, and the population dropped to a balanced level. When living space and nutrition were restored, the population increased again. A sharp decrease in fecundity could also be one of the reasons leading to population fluctuation. If living space and nutrition were not limited, the situation might change. Artificial changes in natural geographic features should always be carefully estimated and carried out. The construction of a dam in the Senegal River in west Africa caused expansion of foci of S. haematobium, provided new habitats for intermediate hosts and changed the environment in the water to benefit snail fecundity[11]. Dams in the Senegal basin could also increase schistosomiasis by blocking the migration of snail-eating river prawns[12]. In northeast Thailand, the operation of the Pak-Mun dam increased the population density of Neotricula aperta, the intermediate host of S. mekongi, in the short term[13]. In 
China, Yang et al. found that after construction of the Three Gorges Dam, there was a convex relationship between flooding duration and spring or autumn 0 . hupensis density; the snail density was the highest when flooding lasted approximately 4 to 5 months[14]. Previous study on the susceptibility of $O$. hupensis breeding in Weishan Lake indicated a maximum infection rate of $62.22 \%$ [15]. A survey in 2009 indicated that more than $70 \%$ of boatmen $(n=2086)$ in Weishan Lake were not aware of the risk of schistosomiasis, more than $93 \%$ of boatmen had history of direct water contact, and $97.75 \%$ of participants had not taken any precautions[16]. However, based on our results and others, 0 . hupensis, once induced by SNWD Project, could establish a habitat in Weishan Lake and increase the risk of transmission of schistosomiasis.

After 12 years of culture in Weishan Lake, decreases (not significant) in shell length (L), shell width (W) and apertures width (AW) were observed after 2005 in comparison to 0 . hupensis from the Yangtze River. However, significant changes were observed in sperms and oocytes of snails breeding in Weishan Lake. For sperms from Weishan Lake snails, the absence of a $9+2$ ACF in the tails could result in sperms lacking mobility. For oocytes, the swelling nuclei, decreased endoplasmic reticulum, pale vesicles and lipidosomes and absent chromatin indicated poor nutritional environment and poor status of oocytes. Thus, the fecundity of $O$. hupensis breeding in Weishan Lake with low sperms and oocytes decreased sharply with time. However, even with low fecundity, the snail population is still present breeding cages in Weishan Lake, and viable eggs could still be found by 2016. Unlike other freshwater snails (Biomphalaria. spp and Bulinus. spp) of other schistosomes (S. mansoni and S. haematobium), O. hupensis is amphibious and more resilient to temperature change. In moist soil, the $50 \%$ hibernation temperature of O. hupensis is $5.87^{\circ} \mathrm{C}$ and the $50 \%$ lethal temperature is $-2.72{ }^{\circ} \mathrm{C}[17]$. In Weishan Lake, the average temperature is $14.4^{\circ} \mathrm{C}$, and there are more than 275 days above $-2.72{ }^{\circ} \mathrm{C}$. It could be an evolutionary strategy for 0 . hupensis to trade off its fecundity to survive in harsh winters by saving unnecessary energy. Similar evidence has been found in other species. Acclimation to cold temperatures led to less efficient male courtship and a significant decrease in the likelihood of mating in Drosophila melanogaster[18]. The cow tick, $R$. microplus, trades off reproductive fitness under low temperatures to maintain the ability to transmit pathogens[19].

\section{Conclusion}

Our study suggested that $O$. hupensis could survive for 12 years in Weishan Lake in Shandong Province, which was previously considered to be an unsuitable environment. Abnormal development of germ cells might reflect a survival strategy in which the snail trades its fecundity to survive harsh winters. These results have provided a solid baseline for long-term research on monitoring the invasion of 0 . hupensis to northern China via the artificial water resource project.

\section{Methods}

\section{Field transplant experiments}


Two thousand adult $O$. hupensis were selected from original habitat along the Yangtze River in Yangzhou City of Jiangsu Province ( $\left.32^{\circ} 39^{\prime} \mathrm{N}, 119^{\circ} 42^{\prime} \mathrm{E}\right)$ and transplanted to isolated snail cages (200

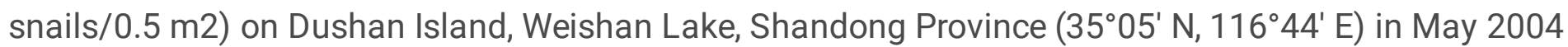
(Fig. 1). The cages (size: length $\times$ height $\times$ width, $1000 \mathrm{~cm} \times 50 \mathrm{~cm} \times 50 \mathrm{~cm}$ ) were made from steel bars covered with $0.25 \mathrm{~mm}$ diameter nylon net to prevent snails from escaping. The cages were filled with soil including plants from the marshland to a depth of $10 \mathrm{~cm}$, and at least $1 / 3$ of area of the cage bottom area was always below the water level (Fig. 2).

From October 2005 to October 2016, every year, O. hupensis bred in isolated snail cages on Dushan Island were collected. Meanwhile, 0 . hupensis from their traditional habitats along Yangtze River in Yangzhou City of Jiangsu Province (32 $\left.39^{\prime} \mathrm{N}, 119^{\circ} 42^{\prime} \mathrm{E}\right)$ were also collected as controls. Live snails were brought to the laboratory. Adult and juvenile snail number s were counted, and their morphological features were measured.

\section{Population And Morphological Measurement Of Snails}

All the soil from $100 \mathrm{~cm} \times 50 \mathrm{~cm}(1 / 10$ of total soil) areas in the breeding cages were randomly selected and transported to the laboratory. Snails were isolated by nylon net elutriation. Live snail numbers were counted to calculate the total population of snails, and then the same amount of new soil from nearby marshland and more than half of inspected snails were replaced. The inspected areas were marked and excluded from the next year's sampling.

The shell length (L), shell width (W), product of apertures (AP), aperture length (AL), aperture width (AW), labial ridge thickness (LRT) and longitudinal ridge number (LRN) of the collected snails were measured.

\section{Transmission electron microscopic (TEM) observation of $O$. hupensis gonads}

Active individuals of $O$. hupensis were selected and identified as male or female. Intact ovaries and testis from specimens with no mechanical damage were removed by a dissecting needle under a microscope, washed 5 times with cold phosphate-buffered saline solution $\left(4{ }^{\circ} \mathrm{C}, \mathrm{pH} 7.4\right)$, and then immersed in $2.5 \%$ glutaraldehyde at $4{ }^{\circ} \mathrm{C}$ for $24 \mathrm{~h}$ with a light-tight seal. A total of 4 specimens of testis and ovaries of snails isolated from both Yangtze River and Weishan Lake were collected for transmission electron microscopic observation. Specimens were observed under a transmission electron microscope (Tecnai G2 Spirit Twin, FEI Company, USA).

\section{Declarations}

\section{Ethics approval and consent to participate}

The experimental project was reviewed and approved by the Institutional Ethics Committee of the Shandong Institute of Parasitic Diseases (SIPD), Shandong First Medical University \& Shandong Academy of Medical Sciences (Jining, Shandong).

\section{Consent for publish}


Not applicable.

Availability of data and materials

All relevant data are within the paper.

Competing interests

The authors have declared that no competing interests exist.

\section{Funding}

The present study was supported by the National Natural Science Foundation of China (NSFC) (Grant No. 81471985, 81672059) and The Innovation Project of Shandong Academy of Medical Sciences.

\section{Authors' contributions}

ZCX and LX conceived and designed the experiments. ZX, MF performed the experiments. WZD analyzed the data. WJL contributed reagents/ materials/ analysis tools. ZX, MF and ZCX wrote the paper, all the authors have read and approved the final manuscript.

\section{Acknowledgments}

We thank Chief Physician Huang Yixin and Researcher Yang Kun from the Jiangsu Institute of Parasitic Diseases, People's Republic of China for providing Oncomelania hupensis specimens.

\section{References}

1. Zhou XN, Bergquist, R., Leonardo, L., Yang, G.J., Yang, K., Sudomo, M., Olveda, R.: Schistosomiasis japonica control and research needs. Advances in parasitology 2010, 72:145-178. .

2. Hauswald AK, Remais, J.V., Xiao, N., Davis, G.M., Lu, D., Bale, M.J., Wilke, T.: Stirred, not shaken genetic structure of the intermediate snail host Oncomelania hupensis robertsoni in an historically endemic schistosomiasis area.pdf. Parasites and Vectors 2011, 4:206.

3. Zhou XN, Yang, K., Hong, Q.B., Sun, L.P., Yang, G.J., Liang, Y.S., Huang, Y.X.: Prediction of the impact of climate warming on transmission of schistosomiasis in China. Chinese Journal of Parasitology and Parasitic Diseases 2004, 22(5):262-265.

4. Huang YX, Hang, D.R., Tang, H.P., Sun, D.K., Zhou, C.H., Gao, J.B., Zheng, B., Hu, G.Q., Li, Q., Huang, Y.J., She, G.S., Ren, Z.Y.: Further study on possibility of diffusion of Oncomelania hupensis with water in river channels of the east route of South-to-North Water Diversion Project. Chinese Journal of Schistosomiasis Control 2014, 26(6):608-612.

5. Saarman NP, Kober KM, Simison WB, Pogson GH: Sequence-Based Analysis of Thermal Adaptation and Protein Energy Landscapes in an Invasive Blue Mussel (Mytilus galloprovincialis). Genome Biology and Evolution 2017, 9(10):2739-2751. 
6. Oellermann M, Strugnell JM, Lieb B, Mark FC: Positive selection in octopus haemocyanin indicates functional links to temperature adaptation. BMC Evolutionary Biology 2015, 15(1).

7. Polgar G, Khang TF, Chua T, Marshall DJ: Gross mismatch between thermal tolerances and environmental temperatures in a tropical freshwater snail: Climate warming and evolutionary implications. Journal of Thermal Biology 2015, 47:99-108.

8. Koštál V, Rozsypal, J., Pech, P., Zahradníčková, H., Šimek, P.: Physiological and biochemical responses to cold and drought in the rock-dwelling pulmonate snail, Chondrina avenacea. Journal of Comparative Physiology B 2013, 183(6):749-761.

9. Zhang LJ, Xu, Z. M., Qiang, Y. J,, Dang, H., Lv, S., Xu, J., Li, S. Z., Zhou, X. N.: Endemic status of schistosomiasis in People's Republic of China in 2016. Chinese Journal of Schistosomiasis Control 2017, 29(6):669-677.

10. Wang W, Liang, Y.S., Dai, J.R., Huang, Y.X.: Impact of the construction of the South-to-North Water Diversion Project on distribution of Oncomelania hupensis, the intermediate host of Schistosoma japonicum in China. Acta Ecologica Sinica 2008, 28(9):4235-4245.

11. Southgate VR: Schistosomiasis in the Senegal River Basin: before and after the construction of the dams at Diama, Senegal and Manantali, Mali and future prospects. Journal of Helminthology 1997, 71(2):125-132.

12. Sokolow S, H, Jones, I.J., Jocque, M., La, D., Cords, O., Knight, A., Lund, A., Wood, C.L., Lafferty, K.D., Hoover, C.M., Collender, P.A., Remais, J.V., Lopez-Carr, D., Fisk, J., Kuris, A.M., De Leo, G.A.. Nearly 400 million people are at higher risk of schistosomiasis because dams block the migration of snail-eating river prawns..pdf>. Philosophical transactions - Royal Society Biological sciences 2017, 372(1722):20160127.

13. Zhou XN, Attwood, Stephen W., Upatham, E. Suchart: A Population Growth Trend Analysis for Neotricula aperta, the Snail Intermediate Host of Schistosoma mekongi, after Construction of the Pak-Mun Dam. PLoS Neglected Tropical Diseases 2013, 7(11):e2539.

14. Yang Y, Gao J, Cheng W, Pan X, Yang Y, Chen Y, Dai Q, Zhu L, Zhou Y, Jiang Q: Three Gorges Dam: polynomial regression modeling of water level and the density of schistosome-transmitting snails Oncomelania hupensis. Parasites \& Vectors 2018, 11(1).

15. Liang YS, Dai, J. R., Song, H. T., Jiang, B. Q., Jiang, Y. J., Hang, P. Y., Huang, Y. X., Miao, F., Zhu, Y. C., Xiao, R. W.: Survival of Oncomelania hupensis snails in the north of China and their susceptibility to Schistosoma japonicum. Chinese Journal of Parasitology and Parasitic Diseases 2002, 15(1):39-41.

16. Wang YB, Miao, F., Wei, Q.K., Fu, Z.Y., Zhao, C.L., Chen, X.X., Liu, X., Yin, Y.H., Ma, C.J., Zhang, Z.X., Fang, Z.C., Wang, J., Wei, C.Y.: Investigation on schistosome infection and KAP about schistosomaisis control among boatmen in Weishan Lake region, Shandong Province. Chinese Journal of Schistosomiasis Control 2009, 21(6):544-546.

17. Hong QB, Zhou, X.N., Sun, L.P., Yang, G.J., Huang, Y.X., Yang, K.: Impact of global warming on the transmission of schistosomiasis in China II: the hibernation and lethal temperature of Oncomelania hupensis in laboratory. Chinese Journal of Schistosomiasis Control 2002, 14(3):192-194. 
18. Broughton SJ, Everman ER, Delzeit JL, Hunter FK, Gleason JM, Morgan TJ: Costs of cold acclimation on survival and reproductive behavior in Drosophila melanogaster. Plos One 2018, 13(5):e0197822.

19. Esteves E, Pohl PC, Klafke GM, Reck J, Fogaça AC, Martins JR, Daffre S: Low temperature affects cattle tick reproduction but does not lead to transovarial transmission of Anaplasma marginale. Veterinary Parasitology 2015, 214(3):322-326.

\section{Figures}

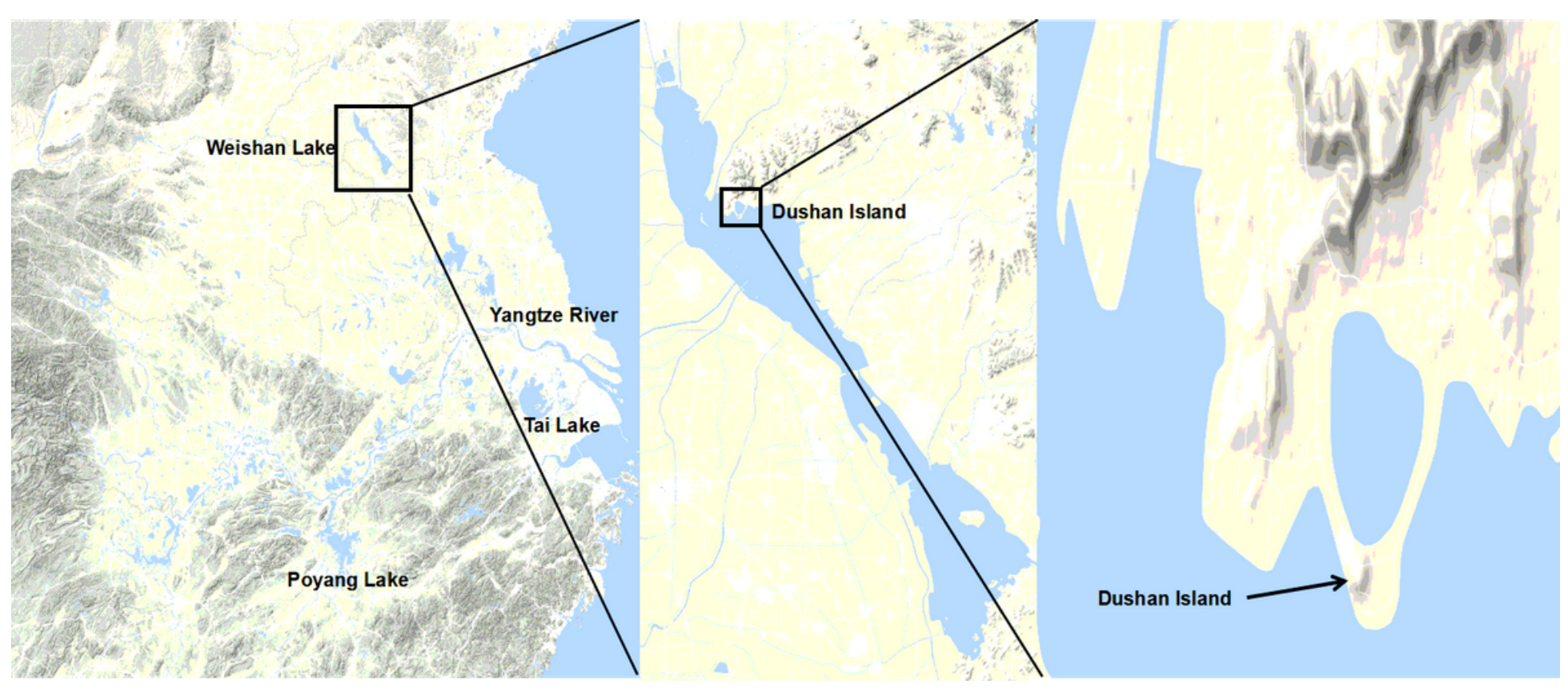

\section{Figure 1}

Geographic location of Dushan Island in Weishan Lake, Shandong Province, China. Note: The designations employed and the presentation of the material on this map do not imply the expression of any opinion whatsoever on the part of Research Square concerning the legal status of any country, territory, city or area or of its authorities, or concerning the delimitation of its frontiers or boundaries. This map has been provided by the authors. 


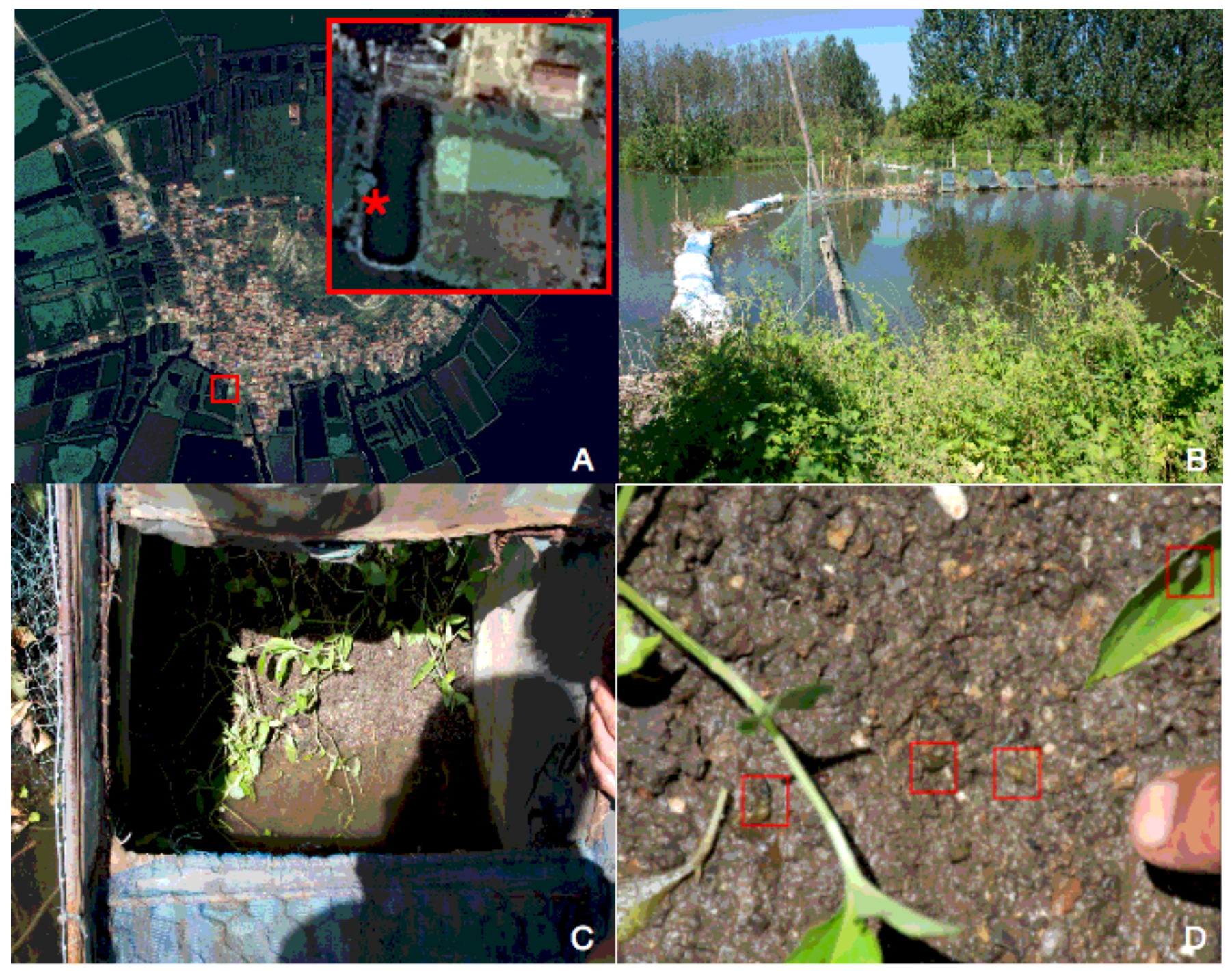

\section{Figure 2}

Pictures of field transplantation of 0 . hupensis in Dushan Island in Weishan Lake. A, satellite picture of transplantation field on Dushan island of Weishan Lake (red frames, * indicates where breeding cages were planted). $B$, breeding cages in a abandoned fish pond. $C$, inside view of a breeding cage. $D, 0$. hupensis (highlighted in red frames) inside a breeding cage. 

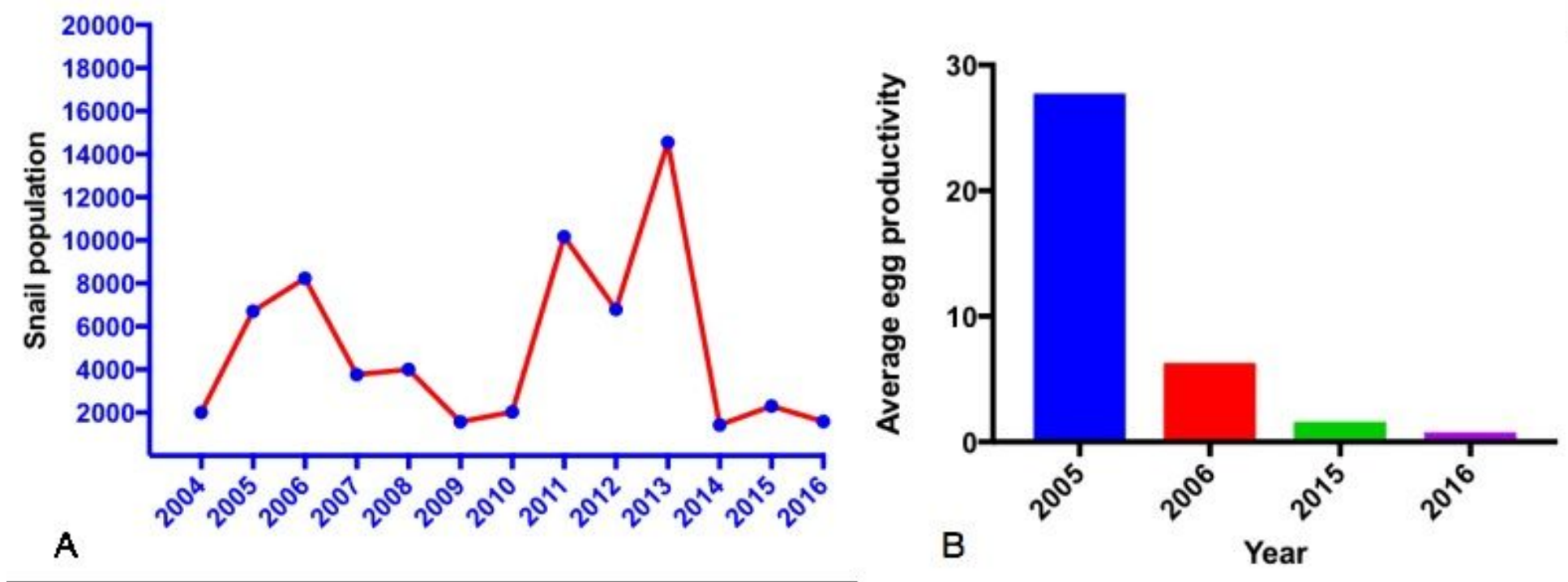

Figure 3

Population curve and fecundity of 0 . hupensis in Weishan Lake, 2004-2016 A, Population curve of 0. hupensis in Weishan Lake, 2004-2016. B, Fecundity of snails of Weishan Lake in 2005, 2006, 2015 and 2016.

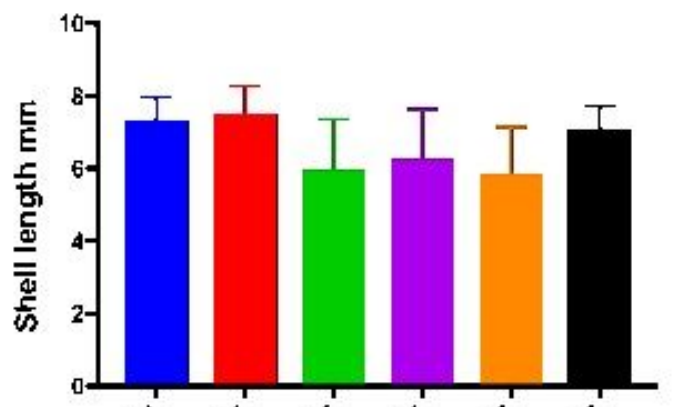

A

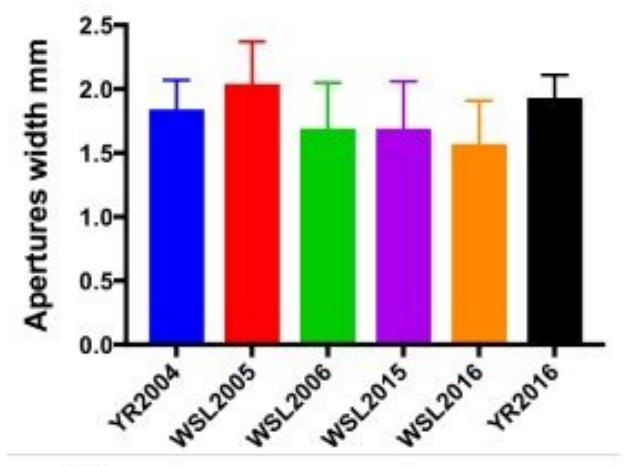

D
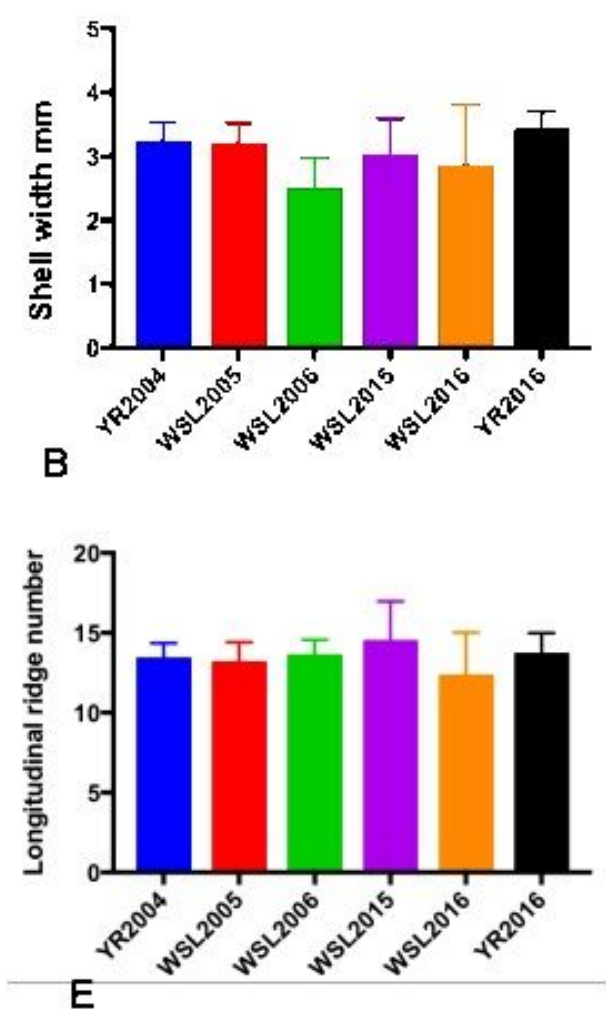

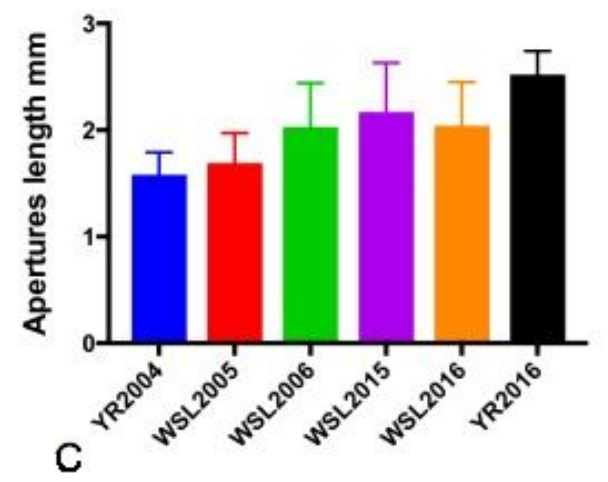

Figure 4

Morphological features of O. hupensis in Weishan Lake and Yangtze River. A, shell length. B, shell width. C, apertures length. D, apertures width. E longitudinal ridge number. YR: Yangtze River, WSL: Weishan Lake. Numbers after abbreviation indicate years of collection. 


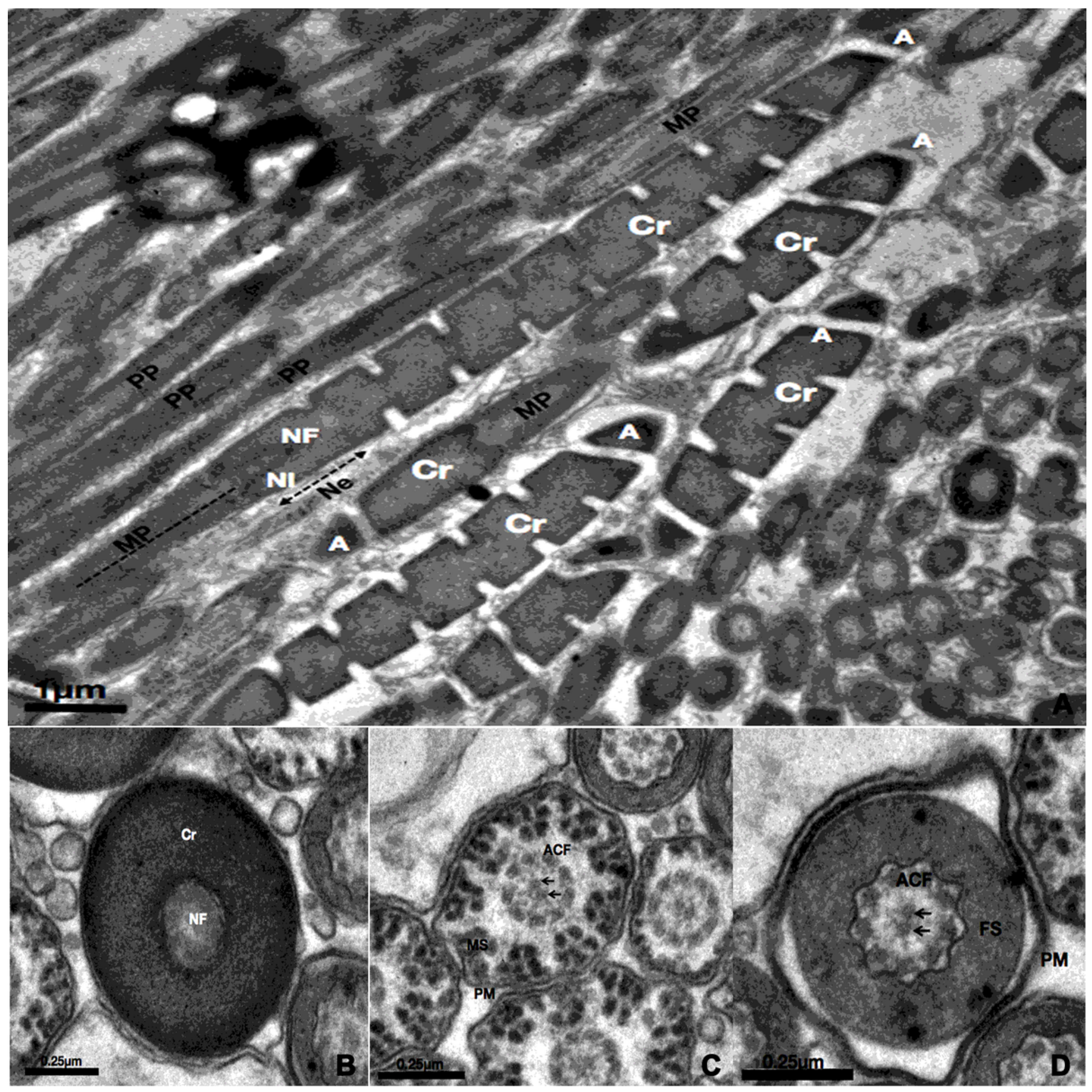

\section{Figure 5}

Ultra-structures of $\mathrm{O}$. hupensis male gonads collected from Yangtze River A, longitudinal sections of sperm cell head A: arcosome, Cr: chromatin, NF:nuclear fossa, Nl: nuclear invagination, Ne: neck region, MP: middle piece of tail, PP: principle piece of tail, bar $=1 \mu \mathrm{m}$. B, cross section of sperm neck region, bar $=0.25 \mu \mathrm{m}$. C, cross section of middle piece of sperm tail, ACF: axoneme coarse fibers, MS: mitochondrial sheath, PM: plasma membrane, bar $=0.25 \mu \mathrm{m}$. D, cross section of principle piece of tail, FS: fibrous sheath, bar $=0.25 \mu \mathrm{m}$. 


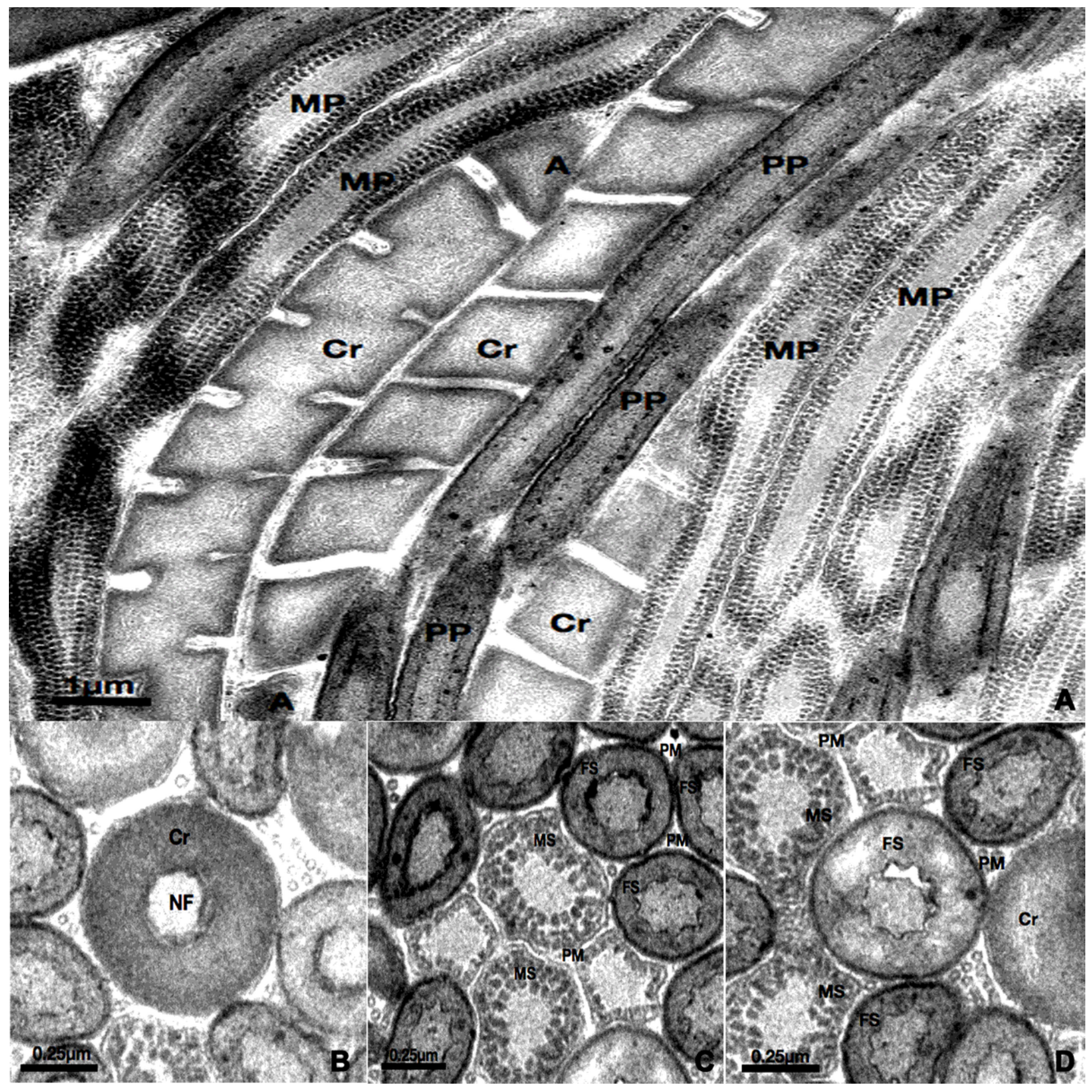

Figure 6

Ultra-structures of $\mathrm{O}$. hupensis male gonads collected from Weishan Lake A, longitudinal sections of sperm cell head A: arcosome, Cr: chromatin, MP: middle piece of tail, PP: principle piece of tail, bar $=1 \mu \mathrm{m}$. $B$, cross section of sperm neck region, bar $=0.25 \mu \mathrm{m}$. C, cross section of middle piece of sperm tail, ACF: axoneme coarse fibers, MS: mitochondrial sheath, PM: plasma membrane, bar $=0.25 \mu \mathrm{m}$. D, cross section of principle piece of tail, FS: fibrous sheath, bar $=0.25 \mu \mathrm{m}$. 


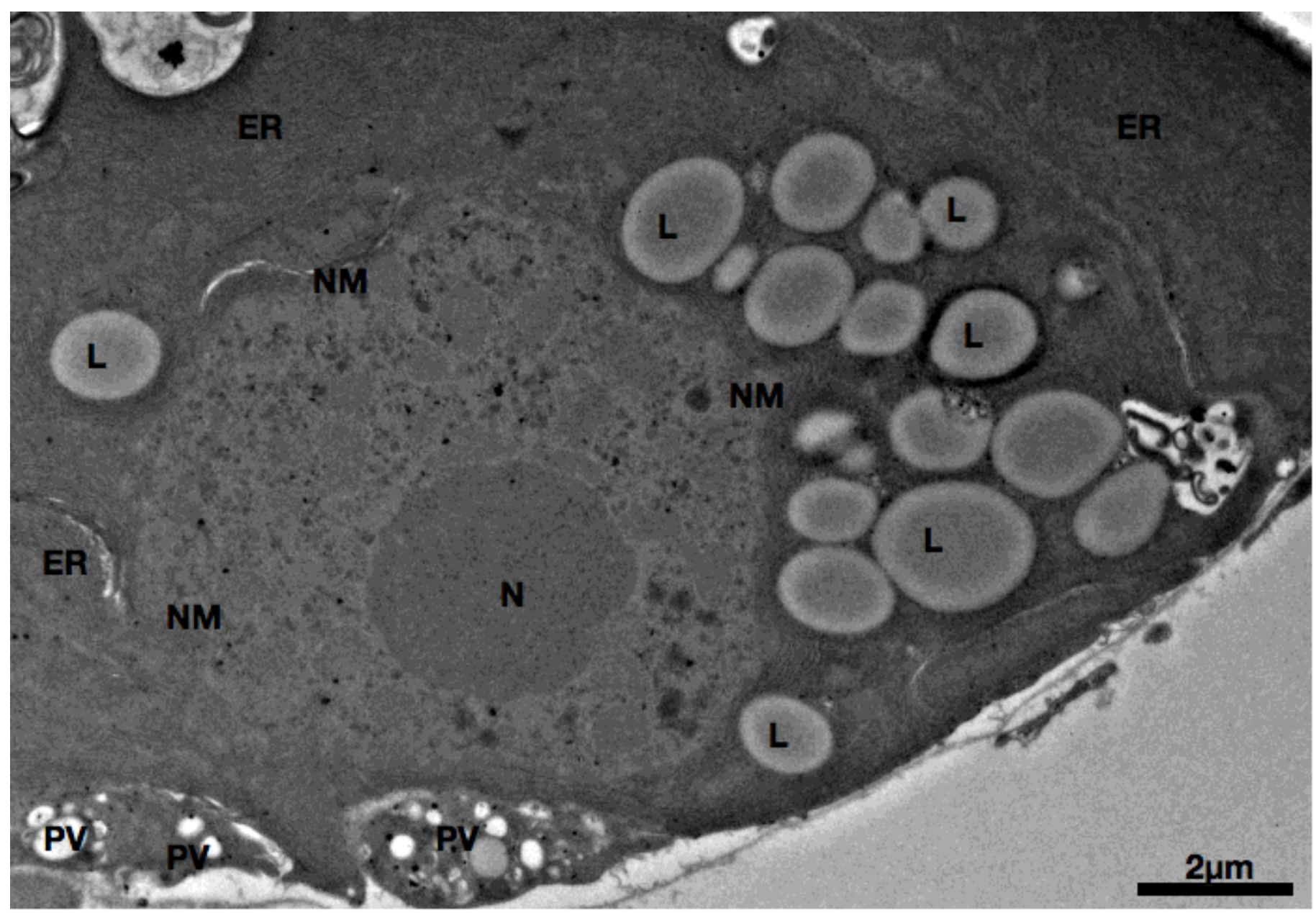

\section{Figure 7}

Ultra-structures of O. hupensis female gonads collected from Yangtze River. N: nucleolus, NM: Nuclear membrane, ER: endoplasmic reticulums, L: lipidosome, PV: pale vesicles, bar $=2 \mu \mathrm{m}$. 


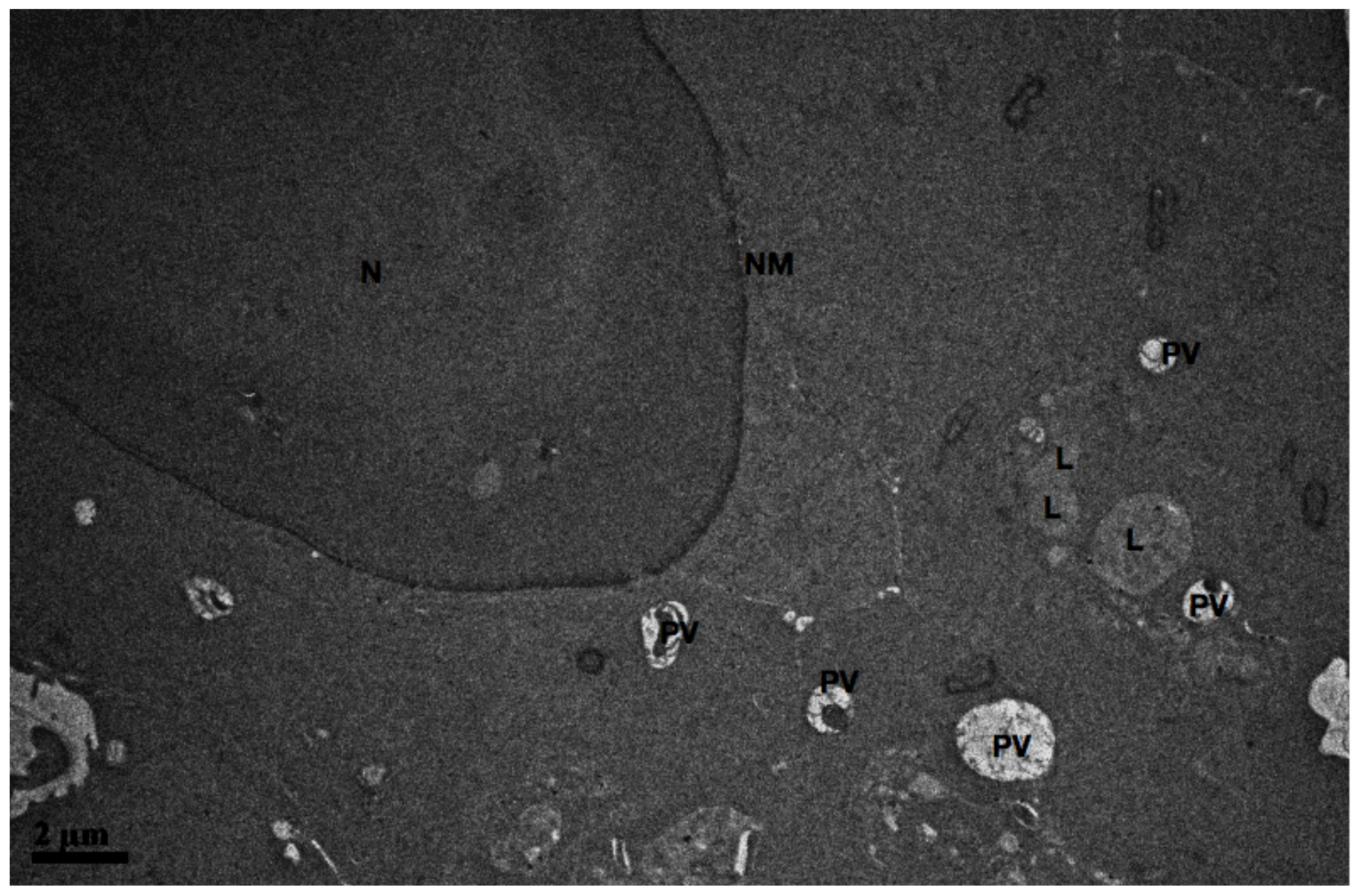

\section{Figure 8}

Ultra-structures of $\mathrm{O}$. hupensis female gonads collected from Weishan Lake. N: nucleolus, NM: Nuclear membrane, L: lipidosome, PV: pale vesicles, bar $=2 \mu \mathrm{m}$. 